[in press, Archives of Sexual Behavior, October 2015]

\title{
Monogamy versus Consensual Non-Monogamy: Alternative Approaches to Pursuing a \\ Strategically Pluralistic Mating Strategy
}

Justin K. Mogilski ${ }^{1,2}$, Stacy L. Memering ${ }^{1}$, Lisa L. M. Welling ${ }^{1}$, Todd K. Shackelford ${ }^{1}$

${ }^{1}$ Department of Psychology, Oakland University

${ }^{2}$ To whom correspondence should be addressed at Department of Psychology, Oakland

University, Rochester, MI 48309; e-mail: jkmogils@oakland.edu 


\section{ABSTRACT}

This study examined the frequency of partner-directed mate retention behaviors and several selfand partner-rated romantic relationship evaluations (i.e.., sociosexuality, relationship satisfaction, mate value, and partner ideal measures) within monogamous and consensually non-monogamous (CNM) relationships. Measures were compared (1) between monogamous and CNM participants and (2) between two concurrent partners within each CNM relationship (i.e., primary and secondary partners). We found that individuals in currently monogamous relationships $(n=123)$ performed more mate retention behaviors compared to those currently in CNM relationships $(n=$ 76). Within CNM relationships, participants reported engaging in more mate retention behaviors with primary partners compared to secondary partners. Likewise, CNM participants reported talking about their extra-dyadic sexual experiences and downplaying these sexual experiences more often with their primary partner compared to their secondary partner. There were no significant differences between ratings of monogamous and primary partners in participants' overall relationship satisfaction. However, monogamous participants reported less satisfaction with the amount of communication and openness they had with their partner compared to CNM participants' reports of their primary, but not secondary, partner. By comparison, CNM participants reported higher overall relationship satisfaction with primary compared to secondary partners and considered their primary partner to be more desirable as a long-term mate than their secondary partner. We interpret these results within the context of previous research on monogamous and CNM relationships and hypothesize that these relationship configurations are alternative strategies for pursuing a strategically pluralistic mating strategy.

KEY WORDS: monogamy, non-monogamy, polyamory, mate retention, mating strategies 


\section{INTRODUCTION}

Mating systems vary in evolutionarily predicted ways in non-humans (Arnold \& Duvall, 1994; Clutton-Brock, 1989; Hardy, Ode, \& Siva-Jothy, 2005) and in humans (Borgerhoff Mulder, 1992; Buss, 2003; Chisholm, 1993; Draper \& Harpending, 1982; Lancaster \& Lancaster, 1987; Nakahashi \& Horiuchi, 2012; Schmitt, 2005; Thornhill \& Gangestad, 2008; Wilson \& Daly, 1997). Anthropological and cross-cultural studies have identified several predictors of the prevalence and structure of human mating systems within particular environments, such as the relative distribution of wealth (Barber, 2008; Marlowe, 2000), population sex ratio (Schmitt, 2005), and pathogen prevalence (Low, 1990), that have comparable predictors in non-human populations (Alcock, 1980; Hamilton \& Zuk, 1982). Similarly, population measures of human sociosexuality (i.e., a measure of individual differences in human mating strategies) vary across nations with social and ecological characteristics of the local environment (Schmitt, 2005). For example, in environments with higher rates of mortality and lower indices of economic resources, national levels of sociosexuality trend toward patterns that promote monogamy and greater investment in long-term relationships, whereas in environments with lower rates of mortality and higher indices of economic resources, there are trends toward promiscuous mating systems in which individuals are quicker to have sex and experience less romantic relationship closeness (Lippa, 2009; Schmitt, 2005; Simpson \& Gangestad, 1991). Trade-offs in parenting effort versus mating effort (i.e., long-term versus short-term mating strategies) (Buss \& Schmitt, 1993) predict these variations in human mating systems (Gangestad \& Simpson, 2000).

Relationship researchers have added to current understandings of human mating systems by characterizing subsets of non-monogamy and contemporary social standards of nonmonogamy. Non-monogamy exists in a variety of forms across cultures, including serial pair- 
bonding (i.e., serial monogamy), polygyny (i.e., the marriage of one man to two or more women), polyandry (i.e., the marriage of one woman to two or more men), polygynandry (i.e., group marriage), communal living, non-consensual non-monogamy (i.e., infidelity), and "open" pair-bonding (Loue, 2006). Some researchers further distinguish different forms of nonmonogamy, including swinging (Jenks, 1998), open relationships (Hyde \& DeLamater, 2000), and polyamory (Barker, 2005; Klesse, 2006), referred to collectively as consensually nonmonogamous (CNM) relationships (i.e., relationships in which both partners have openly agreed that they and/or their partners will have other sexual and/or romantic partners) (Barker \& Langdridge, 2010; Conley, Moors, Matsick, \& Ziegler, 2012a). There are also a variety of relationship configurations or "models" described for CNM relationships. Barker and Langdridge (2010) outlined some of the most commonly known models, including the primary/secondary model (i.e., one partnership is regarded as the main relationship and any other relationships revolve around the couple), triads or quads (i.e., three or four people comprise the main unit), Vstructures (i.e., one person is equally involved with two others), and other broader poly "webs" or families. The primary/secondary model is the most commonly practiced form of consensual non-monogamy, with over a third of CNM individuals reporting being in a primary/secondary relationship and another third reporting being in a V-structured relationship (Barker, 2005).

In recent years, there has been interest in empirically characterizing monogamy alongside other CNM romantic relationship configurations. For example, Barker and Langdridge (2010) noted that romantic and interpersonal relationship processes typically investigated within the context of monogamous relationships are not as frequently considered within the context of CNM relationships. Furthermore, certain lay beliefs about the advantages and disadvantages of being in a monogamous versus CNM relationship (e.g., sexual health benefits, increased sexual 
frequency, and decreased experiences of jealousy) are inconsistent with actual or predicted differences identified in the scientific literature (Conley et al., 2012a; Conley, Ziegler, Moors, Matsick, \& Valentine, 2012c). These considerations highlight the theoretical and practical importance of expanding our current understanding of CNM relationships relative to monogamous relationships.

A number of studies have used qualitative and interview-based designs to compare monogamous and CNM relationships (Barker, 2005; de Visser and McDonald, 2007; Klesse, 2005, 2006; Pallotta-Chiarolli, 2006; Ritchie \& Barker, 2007; Robinson, 2013; Sheff, 2005, 2006; Wosick-Correa, 2010). Fewer studies have systematically compared monogamous and CNM relationships using quantitative analyses. Some studies employing the latter strategy have characterized these similarities and differences by measuring self-perceptions and reported behavior of individuals in different types of relationships. For example, Morrison, Beaulieu, Brockman, and Beaglaoich (2013) compared the responses of self-identified polyamorous and monogamous individuals who completed measures of relationship satisfaction and sociosexuality. They found that polyamorous participants, compared to monogamous participants, reported greater intimacy in their relationships, more favorable attitudes toward casual sexual activity, and more casual sexual partners. Likewise, Conley, Moors, Ziegler, and Karathanasis (2012b) found that sexually unfaithful individuals within monogamous relationships were more likely to engage in riskier sexual behaviors than CNM individuals both within their current relationship and with extradyadic sexual partners. van Anders, Hamilton, and Watson (2007) also found that both men and women in polyamorous relationships had higher levels of testosterone compared to participants in monogamous relationships, even after controlling for reported sex drive and sociosexuality. 
Only one study has examined differences in how individuals within CNM relationships perceive each of their partners. To assess how need fulfillment with one partner influences relationship outcomes in a concurrent relationship, Mitchell, Bartholomew, and Cobb (2013) had participants in polyamorous relationships complete measures of need fulfillment, relationship satisfaction, and relationship commitment for two concurrent partners. They found that participants not only reported high need fulfillment and relationship satisfaction in both relationships, but that need fulfillment with one partner did not predict commitment to the other partner. However, they found a small but statistically significant negative association between participants' relationship satisfaction with each partner, such that greater satisfaction with one partner predicted lower satisfaction with the other partner. This provided limited evidence for a "contrast model," which posits that having relationship needs met by one partner may threaten the relationship with another partner. These findings suggest that, although dyadic relationships within CNM relationships function relatively independently from one another, there may be actual or perceived conflict among partners in non-monogamous relationships for relational resources (e.g., emotional support, financial resources, sexual access).

\section{Mate Retention}

Mate retention behaviors (i.e., effort devoted to preventing the loss of a romantic partner) were identified in humans by Buss (1988), who categorized 104 acts into 19 specific mate retention tactics and five categories: Direct Guarding, Intersexual Negative Inducements, Intrasexual Negative Inducements, Positive Inducements, and Public Signals of Possession. This led to the development of the Mate Retention Inventory (MRI) and MRI-Short Form (MRI-SF) (Buss, Shackelford, \& McKibbin, 2008). Scores on the MRI predicted a number of romantic relationship outcomes, behaviors, and attitudes in married (Buss \& Shackelford, 1997) and 
undergraduate couples (Buss, 1988), in non-American samples (Kardum, Hudek-Knežević, \& Gračanin, 2006; Miguel \& Buss, 2011), and in both heterosexual and homosexual romantic relationships (VanderLaan \& Vasey, 2008). Mate retention behaviors vary in evolutionarily predicted ways with men's perceptions of the risk of their partner's infidelity and sperm competition (Starratt, Shackelford, Goetz, \& McKibbin, 2007), the phase of their female partner's ovulatory cycle (e.g., Gangestad, Thornhill, \& Garver, 2002), their female partner's use of hormonal contraceptives (Welling, Puts, Roberts, Little, \& Burriss, 2012), and men's selfesteem (Holden et al., 2014), as well as with both men's and women's self- and partnerevaluations of mate value (Miner, Starratt, \& Shackelford, 2009; Starratt \& Shackelford, 2012), partner-directed oral sex behavior (Pham \& Shackelford, 2013; Sela, Shackelford, Pham, \& Euler, 2015), and sociosexuality (Kardum, Hudek-Knežević, \& Gračanin, 2006). Given the ubiquity of mate retention behaviors and their theoretical and practical importance in human mating, investigating the use of mate retention tactics among individuals in CNM relationships may assist in understanding CNM relationship dynamics and, by comparison, monogamous relationships.

\section{Research Aims}

In the current study, we compared the frequency of mate retention behaviors enacted toward partners in monogamous relationships and toward different partners within CNM relationships. We also examined similarities and differences in a number of complementary, exploratory measures (i.e., sociosexuality, relationship satisfaction, partner ideal measures, perceptions of mate value discrepancy, and sexual communication) to replicate previous findings (e.g., Brockman \& Beaglaoich, 2013; Mitchell, Bartholemew \& Cobb, 2013; van Anders, Hamilton, \& Watson, 2007) and to provide an explanatory context for predicting differences in 
monogamous and CNM relationships. There is presently no popular theoretical framework from which to predict how CNM relationships are expected to differ relative to monogamous relationships in mate retention behaviors. To that end, our study was exploratory. However, given the value of using an evolutionary perspective in the study of romantic relationships and social behavior (Zeigler-Hill, Welling, \& Shackelford, 2015), we adopted measures that have a well-developed theoretical basis within the evolutionary psychological literature on human mating behavior. Although these measures have been studied extensively within monogamous relationships, no study has yet examined them within CNM relationships. By comparing CNM participants' responses on these measures with responses from monogamous individuals, we sought to add to the current literature examining these two relationship configurations as well as introduce a novel predictive framework from which researchers might begin to systematically study CNM relationships from an evolutionary perspective.

\section{METHOD}

\section{Participants}

Participants ( $n=199,130$ women; age: $M=27.78$ years, $S D=7.53$, range $=18-62)$ were recruited from social media websites, fora, and e-groups frequented by individuals in selfidentified non-monogamous relationships (e.g., non-monogamy sub-Reddit forums, nonmonogamy Facebook groups, etc.). Participants identified as White (89.4\%), Hispanic/Latino (3.5\%), Asian (2.5\%), Black (0.5\%), or other (4\%). Participants reported their sexual orientation using one of three classifications: heterosexual (54.8\%), bisexual (42.7\%), or homosexual (2\%). Women also reported whether they were currently using any form of hormone-based contraception (53.8\% Yes, 46.2\% No), as women's romantic relationship behaviors and attitudes have been show to vary depending on hormonal contraceptive use (reviewed in Welling, 2013). 
All participants reported currently being in a romantic relationship of some type. We used two criteria to differentiate between those currently in monogamous and CNM relationships. First, participants reported whether their romantic relationship was exclusive (i.e., you and your partner agree to not date other people) or non-exclusive (i.e., you and your partner(s) agree that dating other people is permitted) and whether they were currently in a romantic and/or physical relationship with one and only one person or with more than one person. Participants who reported being in an exclusive romantic or physical relationship with one and only one person were classified as monogamous, whereas those who reported being in a non-exclusive romantic or physical relationship with more than one person were classified as CNM. Participants who reported being in a non-exclusive relationship with one and only one person or as being in an exclusive relationship but involved with more than one other person were excluded from analyses, reducing our original sample $(n=228)$ to 199 participants. The aims of the present study were to compare currently and consensually monogamous and CNM relationships and it was not clear whether the excluded relationship configurations represented one type of relationship or the other. For example, a couple may be open to CNM (non-exclusive), but may not currently be in a relationship with more than one person. Alternatively, an individual may report being in an exclusive relationship, yet be emotionally/physically involved with more than one person, which could imply either consensual or non-consensual non-monogamy (i.e., infidelity). These distinctions are consistent with previous empirical research (Mitchell, Bartholomew, \& Cobb, 2013; Morrison et al., 2013) and allow us to focus on currently and consensually monogamous/non-monogamous romantic relationships.

Using these criteria, the final sample consisted of 123 monogamous ( 80 women; age: $M=$ 27.22, $S D=7.86$, range $18-62$ years; sexual orientation: $63.4 \%$ heterosexual, $35 \%$ bisexual, 
$0.8 \%$ homosexual) and $76 \mathrm{CNM}$ (50 women; age: $M=28.68, S D=6.94$, range $=18-48$ years; sexual orientation: $40.8 \%$ heterosexual, $55.3 \%$ bisexual, $3.9 \%$ homosexual) participants. CNM participants reported their current number of partners (44.7\% two partners, $34.2 \%$ three partners, $15.8 \%$ four partners or more; $M=2.83$ partners, $S D=1.21$; range $=2-10$ partners) and described their romantic relationship(s) using one or more of the following descriptors: "I am in a primary relationship with one person (i.e., an emotional/sexual relationship characterized by a high degree of commitment, shared life goals, and affection) and in secondary relationships with one or more other people (i.e., close, ongoing emotional/sexual relationship(s), but with a lesser degree of commitment than a primary relationship)" ( $n=54)$, "I am equally involved with only two people" $(n=10)$, "I am equally involved with more than two people" $(n=7)$, and "I am involved in a poly "web," "family," or "intimate network" (i.e., a social web resulting from having romantic relationships among you, your romantic partners, their romantic partners, and so forth)" $(n=19)$. Monogamous participants did not report involvement in any of these relationship structures.

\section{Measures and Procedure}

All measures were presented using the online survey program Qualtrics. Participants were told the purpose of the research was to learn more about how peoples' personalities and romantic relationship experiences affect the way they initiate and maintain romantic relationships and react to imagined partner infidelity.

After providing informed consent, participants answered questions about themselves, including a demographic questionnaire (age, gender, race/ethnicity, and sexual orientation), the Partner Ideal Scale (Fletcher et al., 1999), the Sociosexual Orientation Inventory-Revised (SOIR) (Penke \& Asendorpf, 2008), and mate value discrepancy measures. The Partner Ideal Scale 
consists of 17 items and measures mate preferences by asking participants to indicate how well each item describes their ideal romantic partner (anchors: $1=$ Doesn't describe very well, $7=$ Describes very well). Items compose three factors: warmth-trustworthiness (e.g., understanding, kind, sensitive), vitality-attractiveness (e.g., adventurous, sexy, good lover), and status-resources (e.g., good job, successful, dresses well). The SOI-R comprises 9 items and measures overall orientation toward uncommitted sex. Items compose three latent variables: sociosexual behaviors (e.g., with how many different partners have you had sex within the past 12 months), attitudes (e.g., I can imagine myself being comfortable and enjoying "casual" sex with different partners) and desires (e.g., how often do you have fantasies about having sex with someone with whom you do not have a committed romantic relationship?). Mate value discrepancy measures included self-evaluations in relation to one's peers (e.g., in relation to your peers, how X are you?) on the following attributes: physical attractiveness, financial prospects, social status, being fun/interesting, desirability as a long-term committed relationship or marriage partner, overall desirability, masculinity/feminity (for men and women, respectively), and dominance (anchors: 1 $=$ Not at all/Extremely low, $9=$ Extremely/Extremely high). Responses to mate value discrepancy measures were used to calculate the difference between perceptions of one's own mate value and the mate value of their partner/partners (see below).

Next, participants answered questions about their romantic partner(s). CNM participants were asked:

"Think of the two romantic partners with whom you currently spend the most amount of time. Of these two individuals, now think of the person who best fits the following description: The person you give the most time, energy, and priority in your life. Your relationship with this person includes high levels of intimacy, attraction and commitment; 
shared life paths and goals; similar beliefs with respect to parenting, economics, housing, important values, ongoing emotional support, etc. You could see yourself having a shared lifelong future together with this person. This description may not completely describe either individual, but please think of the person who is best described in this way."

Participants were then asked to provide the first name of their primary partner (i.e., the partner who best fits the description above), the first name of their secondary partner partner, and the gender/sexual orientation of each partner. Using Qualtrics survey logic, each partner's name was inserted into future questions to increase clarity regarding which questions were in reference to each partner (e.g., How physically attractive is John? versus How physically attractive is Mark?). Thus, participants' partners were never referred to as "primary" or "secondary" within the survey. Monogamous participants were also asked to provide their partner's first name, gender, and sexual orientation.

Participants then completed several inventories assessing their perceptions of each romantic partner, including the Partner Ideal Scale (Fletcher et al., 1999), Relationship Satisfaction Scale (Burns, 1983), the 38-item Mate Retention Inventory (MRI-SF) (Buss et al., 2008), the same mate value discrepancy measures participants completed about themselves, and the current relationship length for each partner. The Relationship Satisfaction Scale comprises seven items measuring an individual's satisfaction with aspects of a current romantic relationship (e.g., communication and openness, intimacy and closeness, overall satisfaction with your relationship) (anchors: $1=$ Very dissatisfied, $7=$ Very satisfied). CNM participants also reported how often they talked with their partners about their sexual experiences with other people, and 
how often they downplayed their sexual experiences with other people when talking with their partner(s) (i.e., not telling them how enjoyable it was; anchors: $0=$ Never, $6=$ Every time).

\section{RESULTS}

\section{Self-Evaluations}

SOI-R, Partner Ideal Scale, and self-rated mate value scores were compared across monogamous and CNM participants. Following Penke \& Asendorpf (2008), scores on the SOI-R were averaged to create an overall score $(\alpha=.82)$ and three subcomponents (behaviors, $\alpha=.77$; attitudes, $\alpha=.71$; desires, $\alpha=.80)$. An independent $t$-test showed that CNM participants had higher scores on the SOI-R $(M=3.58, S D=0.71)$ than monogamous participants $(M=3.05, S D$ $=0.70), t(195)=-5.13, p<.001, d=0.75$. This pattern was consistent across all three SOI-R subcomponents (all $p \mathrm{~s}<.001)$. Following Fletcher (1999), Partner Ideal Scale scores were averaged to create three factors: warmth-trustworthiness $(\alpha=.79)$, vitality-attractiveness $(\alpha=$ $.75)$, and status-resources $(\alpha=.83)$. Three independent $t$-tests showed that monogamous and CNM participants' partner ideal scores did not differ for any factor (all $p$ s $>$.45). Similarly, a one-way MANOVA with mate value measures $(\alpha=0.85)$ entered as dependent variables revealed no multivariate effect of relationship type, $F(10,188)=1.03, p>.41$.

A series of chi-square tests showed that CNM participants $(55.3 \%)$ were more likely to report being bisexual compared to monogamous participants $(35.2 \%), \chi^{2}(2, N=198)=11.20, p$ $=.004$. Monogamous participants were more likely to have an opposite-sex $(N=110)$ rather than same-sex $(N=8)$ partner, $\chi^{2}(1, N=118)=88.17, p<.001$. Likewise, CNM participants' primary and secondary partners were both more likely to be opposite-sex (primary: 90.7\%; secondary: $80 \%$ ) than same-sex (primary: $9.3 \%, \chi^{2}(1, N=75)=49.61, p<.001$; secondary: $18.6 \%, \chi^{2}(1, N$ $=75)=28.60, p<.001)$. However, CNM participants' secondary partners were more likely to be 
same-sex $(18.7 \%)$ than monogamous participants' partners $(6.8 \%), \chi^{2}(1, N=198)=6.30, p=$ .012. CNM participants' primary partners were no more likely to be same-sex $(9.2 \%)$ than monogamous partners $(6.8 \%), \chi^{2}(1, N=198)<1$. A McNemar's test showed that secondary partners $(18.7 \%)$ were more likely to be same-sex compared to primary partners $(9.2 \%), p=$ .039 .

\section{Partner Evaluations}

Three comparisons were made for each partner evaluation variable: ratings of monogamous partners versus ratings of CNM primary partners, ratings of monogamous partners versus ratings of CNM secondary partners, and ratings of CNM primary versus ratings of CNM secondary partners. The first two comparisons measured differences between perceptions of monogamous versus CNM partners, whereas the third measured differences between perceptions of partners within a CNM relationship. Although this implies a two-factor structure (i.e., monogamous versus CNM and primary versus secondary), interactions among these variables would be meaningless (i.e., monogamous participants did not answer questions about primary and secondary partners). Therefore, we tested main effects by running two independent-samples $t$-tests (comparing monogamous partners to primary and secondary partners) and one repeatedmeasures $t$-test (comparing primary and secondary partners) for each dependent variable. We used a Bonferroni correction for each set of three analyses to adjust for inflated Type I error.

For three inventories (i.e., the Partner Ideal Scale, Relationship Satisfaction Scale, and MRI-SF), additional analyses were conducted to compare partner differences among individual items or sub-categories within each inventory. Because these item-level analyses were exploratory, we did not correct for inflated Type I error. For overall scores on these inventories (i.e., "overall scores" on the MRI, "overall relationship satisfaction" on the Relationship 
Satisfaction Scale, and "warmth-trustworthiness, vitality-attractiveness, status-resources" scores on the Partner Ideal Scale), a Bonferroni correction was used for each set of three analyses.

\section{Mate Retention}

Following Buss et al. (2008), responses to the 38 items of the MRI-SF were summed to create total mate retention behavior scores $(\alpha=.77)$. Table 1 shows the mean differences and SDs between monogamous and CNM primary/secondary partner evaluations for the overall, domain, and category levels of the MRI-SF. Table 2 shows the mean differences and SDs between CNM primary and secondary partner evaluations for overall, domain, and category levels of the MRI-SF. Monogamous participants reported engaging in more mate retention behaviors with their partner than CNM participants did with either their primary, $t(188)=2.14, p$ $=.033, d=0.32$, or secondary, $t(186)=7.09, p<.001, d=1.12$, partners. Within CNM relationships, participants reported engaging in more mate retention behaviors with their primary partner than with their secondary partner, $t(72)=8.41, p<.001, d=0.99$.

We explored whether participants' mate retention behaviors varied across different mate retention tactics. We calculated participants' scores for the two domains (i.e., Intersexual manipulations and Intrasexual manipulations) and the five categories (i.e., Direct Guarding, Intersexual Negative Inducements, Positive Inducements, Public Signals, and Intrasexual Negative Inducements) of mate retention behaviors identified in the MRI-SF (Buss et al., 2008). There were no significant differences between perceptions of monogamous and CNM primary partners for either domain (both $p$ s $>$.089). However, both domain scores were higher for perceptions of monogamous partners compared to CNM secondary partners (both $p \mathrm{~s}<.001$ ). Among each of the five categories, monogamous individuals reported using more Positive Inducements with their partners compared to CNM participants with their primary partners $(p<$ 
.044 ), but there were no other significant differences (all $p \mathrm{~s}>.245$ ). By contrast, monogamous participants reported engaging in more mate retention behaviors across all five categories compared to CNM participants' reports about their secondary partners (all $p \mathrm{~s}<.019$ ). Moreover, CNM participants reported engaging in more mate retention behaviors with their primary partner than with their secondary partner across both domains and each category (all $p<.001$ ) except for the Intrasexual Negative Inducements category, although this approached significance $(p=.070)$.

\section{Relationship Satisfaction}

Responses to the Relationship Satisfaction Scale items were summed to create an overall relationship satisfaction score $(\alpha=.91)$. There were no significant differences between ratings of monogamous partners $(M=35.52, S D=7.14)$ and $C N M$ primary partners $(M=35.56, S D=$ $7.08), t(197)=-1.28$. However, the difference between ratings of monogamous partners and CNM secondary partners $(M=33.54, S D=7.03)$ was marginally significant, $t(197)=1.97, p=$ $.05, d=0.28$. Moreover, CNM participants reported higher relationship satisfaction with their primary partner $(M=36.43, S D=6.61)$ than with their secondary partner $(M=33.19, S D=$ 7.03), $t(74)=3.80, p<.001, d=.44$. Exploratory analyses of individual items ${ }^{1}$ revealed that monogamous participants reported less satisfaction with the amount of communication and openness they have with their partner than did CNM participants reporting on their relationship with their primary partner,. Monogamous participants reported higher satisfaction with their ability to resolve conflicts, and their intimacy and closeness with their partner compared to CNM participants' reports on secondary partners. CNM participants also reported higher satisfaction with primary than secondary partners in communication and openness, ability to resolve conflicts, affection and caring, and intimacy and closeness.

\footnotetext{
${ }^{1}$ Statistics are available from the corresponding author upon request.
} 


\section{Sexual Communication}

We compared how often CNM participants communicated with their primary and secondary partners about the sex they have with other people. Participants reported talking about the sex they had with other people more often with their primary partner $(M=3.99, S D=1.73)$ than with their secondary partner $(M=3.00, S D=1.55), t(69)=4.59, p<.001, d=0.55$. However, they also report downplaying their sexual experiences with other people more often with their primary partner $(M=1.49, S D=1.55)$ than with their secondary partner $(M=1.14, S D$ $=1.63), t(70)=2.03, p=.047, d=0.24$.

\section{Partner Ideal Scale}

There were no significant differences in how monogamous participants rated their partner on warmth-trustworthiness, vitality-attractiveness, or status-resources compared to CNM participants' primary and secondary partners (all $p s>.208)$. There were also no significant differences in CNM participants' ratings of their primary versus secondary partners (all $p \mathrm{~s}>.10)$. Additional exploration of individual items ${ }^{2}$ revealed that monogamous partners were rated higher on having an attractive appearance compared to CNM primary and secondary partners. By comparison, monogamous partners were rated as less understanding than CNM primary partners, and more supportive than CNM secondary partners. Within CNM relationships, primary partners were rated as more supportive than secondary partners, but secondary partners were rated as more adventurous compared to primary partners.

\section{Mate Value Discrepancy (MVD)}

To examine how CNM participants perceived their own mate value relative to each partner (i.e., primary and secondary), we calculated the discrepancy between participants' self-

\footnotetext{
${ }^{2}$ Statistics are available from the corresponding author upon request.
} 
ratings and partner-ratings for each of the nine mate value measures (MVD scores; i.e., selfratings minus primary/secondary partner ratings). Because masculinity and femininity were only recorded for men and women, respectively, we collapsed these ratings across gender into a "sexual dimorphism" variable. MVD score means and SDs are shown in Table 3. There were significant differences for two measures: overall partner desirability and desirability as a longterm partner. MVD scores for overall desirability were greater for primary partner as opposed to secondary partner ratings, $t(74)=-2.56, p=.013, d=0.31$. MVD scores for long-term partner desirability were also greater for primary compared to secondary partner ratings, $t(74)=-5.83, p$ $<.001, d=0.71$.

To assess the directionality of these differences, we conducted three one-sample $t$-tests comparing overall and long-term desirability MVD scores against zero (i.e., equivalence between self-rated and partner-rated mate value measures) for monogamous, primary, and secondary partners. Monogamous participants viewed their partner as more desirable overall $(M=-0.09, S D$ $=1.87), t(123)=-5.19, p<.001, d=0.94$, and as more desirable as a long-term partner $(M=$ $1.41, S D=1.66), t(123)=-9.40, p<.001, d=1.70$, than themselves. Likewise, $C N M$ participants viewed both primary $(M=-1.19, S D=1.67, t(75)=-5.87, p<.001, d=1.36)$ and secondary partners $(M=-0.64, S D=2.12, t(75)=-2.61, p=.011, d=0.60)$ as more desirable overall than themselves. By contrast, CNM participants rated their primary partner as more desirable than they as a long-term partner $(M=-0.95, S D=1.90, t(75)=-4.31, p<.001, d=$ 1.00), but rated their secondary partners as less desirable than they as a long-term partner $(M=$ $0.77, S D=2.81, t(75)=2.36, p=.021, d=0.55)$

\section{Relationship Duration}


We conducted two one-way ANCOVAs comparing the duration participants reported having been in a romantic relationship with their current partner(s), with age as a covariate. Relationship durations were not normally distributed, so scores for each partner type (i.e., monogamous, CNM primary, and CNM secondary) were log transformed. Means and SDs are reported in years for ease of comparison. Monogamous participants reported having been together longer with their partner $(M=3.80, S D=3.81)$ than did CNM participants with their secondary partner $(M=1.43, S D=1.99), F(1,182)=25.47, p<.001, d=0.34$. However, CNM participants reported having been together longer with their primary partner $(M=5.31, S D=$ 5.01) than did monogamous participants with their partner $(M=3.80, S D=3.81), F(1,182)=$ $4.32, p=.023, d=0.36$. A paired-samples $t$-test comparing CNM primary and secondary partners showed that CNM participants reported having been together longer with their primary partner $(M=5.31, S D=5.01)$ than with their secondary partner $(M=1.43, S D=1.99), t(73)=$ $10.01, p<.001, d=0.60$. However, this effect was marginal after controlling for age, $F(1,68)=$ $3.64, p=.061$, which suggests that this difference was partly driven by older participants whose primary relationships were longer as a function of age.

To control for the possibility that relationship length or participant sexual orientation accounted for the differences among participants' ratings of monogamous, primary, and secondary partners, we re-ran each of our analyses (i.e., mate retention, relationship satisfaction, MVD scores, partner ideal scores, sexual communication) including dyadic relationship length as a covariate and participant sexual orientation as an independent variable for each of the partner evaluation measures. This did not change the significance or directionality of any observed differences. Furthermore, there were no significant interactions with sexual orientation.

\section{DISCUSSION}


We found that monogamous individuals engaged in more mate retention behaviors compared to CNM individuals, and that this was the case for both primary and secondary partners. Specifically, category-level comparisons revealed that monogamous individuals reported engaging in more Positive Inducements with their partner compared to CNM participants with their primary partners, but that there were no significant differences in each of the other four mate retention categories. Why monogamous individuals engage in more mate retention behaviors generally, and Positive Inducement tactics specifically, is not clear. Given that mate retention behaviors increase with perceived infidelity/defection threat (Buss \& Shackelford, 1997; Starratt et al., 2007), it may be that CNM individuals experience fewer feelings of jealousy (Jenks, 1985) or may be less likely to defect from a relationship compared to their monogamous counterparts. Similarly, these two patterns (i.e., fewer feelings of jealousy and a lower likelihood of defection in CNM versus monogamous relationships) could be mediated by the types of mate retention behaviors that are typically employed in monogamous and CNM relationships. Some qualitative accounts describe CNM relationships (e.g., polyamory) as "responsible or ethical non-monogamy" insofar as these relationships are characterized by high levels of emotional closeness and communication about extra-pair sexual desires (Anapol, 1997; Easton \& Liszt, 1997). Our relationship satisfaction results suggested that this may be the case; CNM participants reported greater satisfaction with the amount of communication and openness they had with their primary, but not secondary, partner compared to monogamous participants.

Using qualitative data, Wosick-Correa (2010) concluded that although polyamorous individuals typically reject sexual and emotional exclusivity, these relationships often involve explicitly negotiated agreements about what types of extra-dyadic interactions (e.g., kissing, oral sex, falling in love, vaginal/anal penetration, spending the night together) are permitted by each 
partner. This is unsurprising given that partner infidelity and/or defection is costly for both men and women (Buss, 2002; Gangestad \& Thornhill, 1997; Geary \& Byrd-Craven, 2004; Symons, 1979). Indeed, people tend to prioritize a long-term partner's history of sexual fidelity over other relevant mate attributes (e.g., physical attractiveness and financial stability) (Mogilski, Wade, \& Welling, 2014), are sensitive to cues to infidelity (Schutzwohl, 2005; Schutzwohl \& Koch, 2004; Shackelford \& Buss, 1997; Starratt, McKibbin, \& Shackelford, 2013), typically have strong emotional reactions to partner infidelity (Buss \& Haselton, 2005; Shackelford, LeBlanc, \& Drass, 2000), and adjust their mate retention behaviors according to perceived infidelity threat (Goetz \& Shackelford, 2009; Kaighobadi et al., 2009; McKibbin, Starratt, Shackelford, \& Goetz, 2011). Therefore, expressed openness and communication about a partner's desires for emotional and/or sexual relationships with other people may function as mate retention behaviors that are unique to CNM relationships and may help in processing jealousy. Our sexual communication results provided preliminary evidence for this hypothesis. CNM participants reported talking about the sex they had with other people more often with their primary partner than with their secondary partner. Furthermore, they were more likely to downplay their sexual experiences with other people with their primary compared to secondary partner. Future research could address this by replicating Buss' (1988) study and scale construction using a polyamorous sample.

The importance of further studying mate retention behaviors in CNM samples is underscored by how secondary partners were perceived in comparison to monogamous and primary partners across several measures. Secondary partners were less often the target of mate retention behaviors, both overall and across each category, compared to monogamous and primary partners. Monogamous participants also reported greater satisfaction with their ability to resolve conflicts and with their intimacy and closeness compared to CNM reports on secondary 
partners, whereas CNM participants report greater satisfaction with their openness and communication, ability to resolve conflicts, affection and caring, and intimacy and closeness with their primary compared to secondary partners. From this, it might be inferred that monogamous partners and CNM primary partners are treated similarly. Certainly, we found that the majority of CNM relationships in our sample (i.e., 54 out of 76) reported a primary/secondary relationship configuration whereby one partnership was regarded as the main relationship and other relationships revolved around that dyad (see also Barker \& Langdridge, 2010). Individuals may invest fewer resources in guarding or retaining secondary partners because there is competition for perceived (e.g., emotional investment) or actual (e.g., financial resources, helping behaviors) relational resources. This competition for relationship resources may explain why Mitchell et al. (2013) found that relationship satisfaction with one partner was negatively associated with satisfaction with the other.

Another possibility is that CNM individuals value the relationship with their secondary partner because it fulfills a different set of romantic and/or sexual needs than their primary relationship. Primary partners were rated as more understanding than monogamous partners and more supportive than secondary partners. By comparison, secondary partners were rated as more adventurous than primary partners. Participants also rated their primary partner as more desirable, but rated their secondary partner as less desirable, than themselves as a long-term mate. Therefore, perhaps secondary partners are valued more for their role as a short-term partner, whereas primary partners are more valued for their role as a long-term partner. This does not necessarily imply that individuals within CNM relationships see their secondary relationship as less likely to last. In fact, our results showed that, after controlling for age, there were only marginal differences in how long participants were in a relationship with primary versus 
secondary partners. Rather, this suggests that CNM individuals may practice a strategically pluralistic mating strategy whereby they form romantic and/or sexual relationships with more than one partner to fulfill different relationship needs or desires (i.e., long-term versus shortterm)(see Gangestad \& Simpson, 2000). Men and women in exclusively monogamous relationships sometimes pursue a pluralistic strategy via extra-pair copulation (EPC) (i.e., adultery) or serial monogamy (i.e., having consecutive exclusive relationships with different people). Consensual non-monogamy, by comparison, may constitute an alternative mating strategy that affords an individual both long-term and short-term benefits while minimizing negative interpersonal outcomes inherent to EPC and serial monogamy.

This interpretation was further supported by individual differences among monogamous and CNM participants in our sample. Although monogamous and CNM participants did not differ in how they described their ideal mate or in perceptions of their own mate value, CNM participants reported a more unrestricted sociosexuality than monogamous participants (see also Morrison et al., 2013; van Anders et al., 2007). Furthermore, CNM individuals were more likely to form same-sex partnerships than monogamous individuals and, among CNM relationships, secondary partners were more likely to be same-sex than primary partners. Indeed, one reason for engaging in CNM relationships may be to satisfy sexual needs that are not met by a primary partner, such as desire for a same-sex partner. This suggests that the tendency for an individual to engage in one relationship type or the other may depend more on an individual's preferred mating strategy (i.e., sociosexuality) (see Simpson \& Gangestad, 1991) and sexual orientation than on an individual's mate preferences (i.e., ideal partner characteristics) or mate value. It also suggests that different relationship types (e.g., primary versus secondary) may fulfill different relationship needs (e.g., investment versus sexual variety). This is consistent with previous 
research showing that human mating systems vary systematically across cultures according to the optimal mating strategy within a given local environment (Schmitt, 2005; Gangestad \& Simpson, 2000).

\section{Limitations and Future Directions}

This study had several of limitations that should be taken into consideration. First, we studied a particular subset of contemporary non-monogamous romantic relationships, so results may not generalize across cultures, social contexts (e.g., swinging, group marriage), or relationship configurations (e.g., primary/secondary versus V-structured relationships, quad relationships, or poly families). Furthermore, because our sample was recruited from social media websites frequented by individuals in self-identified CNM relationships, it is possible that our sample of monogamous individuals may not be representative of monogamous individuals in the general population. Our results were also specific to relationships that were currently and consensually non-exclusive. Comparing monogamous relationships in which an individual has been or is currently unfaithful to their partner and CNM relationships with a primary/secondary structure would allow researchers to assess whether secondary partners and EPC partners fulfill similar romantic or sexual needs.

We only collected data from one individual's perspective. Future research should secure information from multiple partners and assess whether partners in the same relationship perceive the relationship dynamics differently depending on their role (i.e., whether they are a primary partner or are a secondary partner). Investigating these relationships or larger poly families using social relations modeling (Kenny, 1994; Kenny \& LaVoie, 1984) to examine actor, partner, and dyad effects might also provide insights into the dynamics of CNM relationships. Furthermore, our sample had a skewed sex ratio that prevented proper analysis of sex differences in 
participants' relationship attitudes and behaviors. Given the theoretical importance of identifying sexual dimorphisms in human mating behavior and cognition (see Conroy-Beam, Buss, Pham, \& Shackelford, 2015), future research should examine potential sex differences.

\section{Conclusion}

This study contributed to a growing body of research on CNM relationships by examining similarities and differences among several self and partner relationship measures. Our results provided preliminary support for the hypothesis that CNM and monogamy are alternative strategies for pursuing a strategically pluralistic mating strategy. This view predicts that individuals in either type of relationship attempt to acquire one or multiple partners who provide both long-term and short-term relationship needs (Gangestad \& Simpson, 2000). Monogamous individuals seek to achieve this by forming an exclusive romantic and/or sexual relationship with either one partner who adequately fulfills both needs, by additionally maintaining one or more clandestine extra-dyadic relationships, or by engaging in serial pair-bonding. By contrast, those who practice non-monogamy seek to achieve this by forming multiple, consensually nonexclusive romantic and/or sexual relationships with more than one partner, where agreements and negotiations function to reduce interpersonal conflict. Adopting this perspective in future research may provide insight into which psychological mechanisms contribute to the decision to pursue a monogamous or CNM relationship. 


\section{REFERENCES}

Alcock, J. (1980). Natural selection and the mating systems of solitary bees. American Scientist, $68,146-153$.

Anapol, D. (1997). Polyamory: The new love without limits. San Rafael, CA: IntiNet Resource Center.

Arnold, S. J., \& Duvall, D. (1994). Animal mating systems: A synthesis based on selection theory. American Naturalist, 143, 317-348.

Baer, B., \& Schmid-Hempel, P. (1999). Experimental variation in polyandry affects parasite loads and fitness in a bumble-bee. Nature, 397, 151-154.

Barber, N. (2008). Explaining cross-national differences in polygyny intensity: Resourcedefense, sex ratio, and infectious diseases. Cross-Cultural Research, 42, 103-117.

Barker, M. (2005). This is my partner and this is my ... partner's partner: Constructing a polyamorous identity in a monogamous world. Journal of Constructivist Psychology, 18, $75-88$.

Barker, M., \& Langdridge, D. (2010). Understanding non-monogamies. New York: Routledge.

Bringle, R., \& Buunk, B. P. (1991). Jealousy and extra-dyadic relationships. In K. McKinney \& S. Sprecher (Eds.), Sexuality in close relationships (pp. 135-153). Hillsdale, NJ: Lawrence Erlbaum.

Burns, D. D. (1993). Ten days to self-esteem. New York: HarperCollins.

Buss, D. M. (1988). From vigilance to violence: Tactics of mate retention in American undergraduates. Ethology and Sociobiology, 9, 291-317.

Buss, D. M. (2002). Human mate guarding. Neuroendocrinology Letters, 23, 23-29.

Buss, D. M. (2003). The evolution of desire (rev. ed.). New York: Basic Books. 
Buss, D. M., \& Haselton, M. G. (2005). The evolution of jealousy. Trends in Cognitive Science, 9, 506-507.

Buss, D. M., \& Schmitt, D. P. (1993). Sexual strategies theory: An evolutionary perspective on human mating. Psychological Review, 100, 204-232.

Buss, D. M., \& Shackelford, T. K. (1997). From vigilance to violence: Mate retention tactics in married couples. Journal of Personality and Social Psychology, 72, 346-361.

Buss, D. M., Shackelford, T. K., \& McKibbin, W. F. (2008). The Mate Retention InventoryShort Form (MRI-SF). Personality and Individual Differences, 44, 322-334.

Chisholm, J. S., Ellison, P. T., Evans, J., Lee, P. C., Lieberman, L. S., Pavlik, Z., ... Worthman, C. M. (1993). Death, hope, and sex: Life-history theory and the development of reproductive strategies. Current Anthropology, 34, 1-24.

Clutton-Brock, T. H. (1989). Review lecture: Mammalian mating systems. Proceedings of the Royal Society of London. B. Biological Sciences, 236, 339-372.

Conley, T. D., Moors, A. C., Matsick, J. L., \& Ziegler, A. (2012a). The fewer the merrier? Assessing stigma surrounding consensually non-monogamous romantic relationships. Analyses of Social Issues and Public Policy, 13, 1-30.

Conley, T. D., Moors, A. C., Ziegler, A., \& Karathanasis, C. (2012b). Unfaithful individuals are less likely to practice safer sex than openly nonmonogamous individuals. Journal of Sexual Medicine, 9, 1559-1565.

Conley, T. D., Ziegler, A., Moors, A. C., Matsick, J. L., \& Valentine, B. (2012c). A critical examination of popular assumptions about the benefits and outcomes of monogamous relationships. Personality and Social Psychology Review, 17, 124-141. 
Conroy-Beam, D., Buss, D. M., Pham, M. N., \& Shackelford, T. K. (2015). How sexually dimorphic are human mate preferences? Personality and Social Psychology Bulletin, 41, 1082-1093.

de Miguel, A., \& Buss, D. M. (2011). Mate retention tactics in Spain: Personality, sex differences, and relationship status. Journal of Personality, 79, 563-586.

de Visser, R., \& McDonald, D. (2007). Swings and roundabouts: Management of jealousy in heterosexual "swinging” couples. British Journal of Social Psychology, 46, 459-476.

Draper, P., \& Harpending, H. (1982). Father absence and reproductive strategy: An evolutionary perspective. Journal of Anthropological Research, 38, 255-273.

Easton, D., \& Liszt, C. A. (1997). The ethical slut. Emeryville, CA: Greenery Press.

Fisher, H. E. (1989). Evolution of human serial pairbonding. American Journal of Physical Anthropology, 78, 331-354.

Fletcher, G. J., Simpson, J. A., Thomas, G., \& Giles, L. (1999). Ideals in intimate relationships. Journal of Personality and Social Psychology, 76, 72-89.

Gangestad, S. W., \& Simpson, J. A. (2000). The evolution of human mating: Trade-offs and strategic pluralism. Behavioral and Brain Sciences, 23, 573-587.

Gangestad, S. W., \& Thornhill, R. (1997). The evolutionary psychology of extrapair sex: The role of fluctuating asymmetry. Evolution and Human Behavior, 18, 69-88.

Gangestad, S. W., Thornhill, R., \& Garver, C. E. (2002). Changes in women's sexual interests and their partner's mate-retention tactics across the menstrual cycle: Evidence for shifting conflicts of interest. Proceedings of the Royal Society of London. Series B: Biological Sciences, 269, 975-982. 
Geary, D. C., Vigil, J., \& Byrd-Craven, J. (2004). The evolution of human mate choice. Journal of Sex Research, 41, 27-42.

Goetz, A. T., \& Shackelford, T. K. (2009). Sexual coercion in intimate relationships: A comparative analysis of the effects of women's infidelity and men's dominance and control. Archives of Sexual Behavior, 38, 226-234.

Hamilton, W. D., \& Zuk, M. (1982). Heritable true fitness and bright birds: A role for parasites? Science, 218, 384-387.

Hardy, I. C., Ode, P. J., \& Siva-Jothy, M. (2005). Mating systems. In M. A. Jervis (Ed.), Insects as natural enemies (pp. 261-298). Dordrecht, Netherlands: Kluewer Academic Publishers.

Holden, C. J., Shackelford, T. K., Zeigler-Hill, V., Miner, E. J., Kaighobadi, F., Starratt, V. G., ... Buss, D. M. (2013). Husband's esteem predicts his mate retention tactics. Evolutionary Psychology, 12, 655-672.

Hyde, J. S., \& DeLamater, J. D. (2000). Understanding human sexuality (7th ed.). New York: McGraw-Hill.

Jenks, R. J. (1985). Swinging: A test of two theories and a proposed new model. Archives of Sexual Behavior, 14, 517-527.

Jenks, R. J. (1998). Swinging: A review of the literature. Archives of Sexual Behavior, 27, 507521.

Kaighobadi, F., Shackelford, T. K., Popp, D., Moyer, R. M., Bates, V. M., \& Liddle, J. R. (2009). Perceived risk of female infidelity moderates the relationship between men's personality and partner-directed violence. Journal of Research in Personality, 43, 10331039. 
Kardum, I., Hudek-Knežević, J., \& Gračanin, A. (2006). Sociosexuality and mate retention in romantic couples. Psihologijsketeme, 15, 277-296.

Kenny, D. A. (1994). Interpersonal perception: A social relations analysis. New York: Guilford Press.

Kenny, D. A., \& La Voie, L. (1984). The social relations model. Advances in Experimental Social Psychology, 18, 142-182.

Klesse, C. (2005). Bisexual women, non-monogamy and differentialist anti-promiscuity discourses. Sexualities, 8, 445-464.

Klesse, C. (2006). Polyamory and its 'others': Contesting the terms of non-monogamy. Sexualities 9, 565-583.

Lancaster, J. B., \& Lancaster, C. S. (1987). The watershed: Change in parental-investment and family-formation strategies in the course of human evolution. In J. B. Lancaster, J. Altmann, A. S. Rossi, \& L. R. Sherrod (Eds.), Parenting across the life span: Biosocial Dimensions (pp. 187-205). Aldine, NY: Transaction Publishers.

Lippa, R. A. (2009). Sex differences in sex drive, sociosexuality, and height across 53 nations: Testing evolutionary and social structural theories. Archives of Sexual Behavior, 38, 631651.

Loue, S. (2006). Multi-bonding: Polygamy, polygyny, polyamory. In S. Loue (Ed.), Sexual partnering, sexual practices, and health (pp. 27-53). New York: Springer.

Low, B. S. (1990). Marriage systems and pathogen stress in human societies. American Zoologist, 30, 325-340.

Marlowe, F. (2000). Paternal investment and the human mating system. Behavioural Processes, 51, 45-61. 
McKibbin, W. F., Starratt, V. G., Shackelford, T. K., \& Goetz, A. T. (2011). Perceived risk of female infidelity moderates the relationship between objective risk of female infidelity and sexual coercion in humans (Homo sapiens). Journal of Comparative Psychology, $125,370-373$.

Miner, E. J., Starratt, V. G., \& Shackelford, T. K. (2009). It's not all about her: Men's mate value and mate retention. Personality and Individual Differences, 47, 214-218.

Mitchell, M. E., Bartholomew, K., \& Cobb, R. J. (2013). Need fulfillment in polyamorous relationships. Journal of Sex Research, 51, 329-339.

Mogilski, J. K., Wade, T. J., \& Welling, L. L. M. (2014). Prioritization of potential mates' history of sexual fidelity during a conjoint ranking task. Personality and Social Psychology Bulletin, 40, 884-897.

Morrison, T. G., Beaulieu, D., Brockman, M., \& Beaglaoich, C. Ó. (2013). A comparison of polyamorous and monoamorous persons: Are there differences in indices of relationship well-being and sociosexuality? Psychology \& Sexuality, 4, 75-91.

Mulder, M. B. (1992). Women's strategies in polygynous marriage. Human Nature, 3, 45-70.

Nakahashi, W., \& Horiuchi, S. (2012). Evolution of ape and human mating systems. Journal of Theoretical Biology, 296, 56-64.

Pallotta-Chiarolli, M. (2006). Polyparents having children, raising children, schooling children. Lesbian and Gay Psychology Review, 7, 48-53.

Penke, L., \& Asendorpf, J. B. (2008). Beyond global sociosexual orientations: A more differentiated look at sociosexuality and its effects on courtship and romantic relationships. Journal of Personality and Social Psychology, 95, 1113-1135. 
Pham, M. N., \& Shackelford, T. K. (2013). Oral sex as mate retention behavior. Personality and Individual Differences, 55, 185-188.

Ritchie, A., \& Barker, M. (2007). Hot bi babes and feminist families: Polyamorous women speak out. Lesbian and Gay Psychology Review, 8, 141-151.

Robinson, M. (2013). Polyamory and monogamy as strategic identities. Journal of Bisexuality, 13, 21-38.

Schmitt, D. P. (2005). Sociosexuality from Argentina to Zimbabwe: A 48-nation study of sex, culture, and strategies of human mating. Behavioral and Brain Sciences, 28, 247-275.

Sela, Y., Shackelford, T. K., Pham, M. N., \& Euler, H. A. (2015). Do women perform fellatio as a mate retention behavior? Personality and Individual Differences, 73, 61-66.

Shackelford, T. K., LeBlanc, G. J., \& Drass, E. (2000). Emotional reactions to infidelity. Cognition and Emotion, 14, 643-659.

Sheff, E. (2005). Polyamorous women, sexual subjectivity, and power. Journal of Contemporary Ethnography, 34, 251-283.

Sheff, E. (2006). Poly-hegemonic masculinities. Sexualities, 9, 621-642.

Simpson, J. A., \& Gangestad, S. W. (1991). Individual differences in sociosexuality: Evidence for convergent and discriminant validity. Journal of Personality and Social Psychology, $60,870-883$.

Schutzwohl, A. (2005). Sex differences in jealousy: The processing of cues to infidelity. Evolution and Human Behavior, 26, 288-299.

Schutzwohl, A., \& Koch, S. (2004). Sex differences in jealousy: The recall of cues to sexual and emotional infidelity in personally more and less threatening context conditions. Evolution and Human Behavior, 25, 249-257. 
Shackelford, T. K., \& Buss, D. M. (1997). Cues to infidelity. Personality and Social Psychology Bulletin, 23, 1034-1045.

Starratt, V. G., McKibbin, W. F., \& Shackelford, T. K. (2013). Experimental manipulation of psychological mechanisms responsive to female infidelity. Personality and Individual Differences, 55, 59-62.

Starratt, V. G., \& Shackelford, T. K. (2012). He said, she said: Men's reports of mate value and mate retention behaviors in intimate relationships. Personality and Individual Differences, 53(4), 459-462.

Starratt, V. G., Shackelford, T. K., Goetz, A. T., \& McKibbin, W. F. (2007). Male mate retention behaviors vary with risk of partner infidelity and sperm competition. Acta Psychologica Sinica, 39, 523-527.

Symons, D. (1979). The evolution of human sexuality. New York: Oxford University Press.

Thornhill, R., \& Gangestad, S. W. (2008). The evolutionary biology of human female sexuality. Oxford University Press.

van Anders, S. M., Hamilton, L. D., \& Watson, N. V. (2007). Multiple partners are associated with higher testosterone in North American men and women. Hormones and Behavior, $51,454-459$.

VanderLaan, D. P., \& Vasey, P. L. (2008). Mate retention behavior of men and women in heterosexual and homosexual relationships. Archives of Sexual Behavior, 37, 572-585.

Welling, L. L. M. (2013). Psychobehavioral effects of hormonal contraceptive use. Evolutionary Psychology, 11, 718-742. 
Welling, L. L. M., Puts, D. A., Roberts, S. C., Little, A. C., \& Burriss, R. P. (2012). Hormonal contraceptive use and mate retention behavior in women and their male partners. Hormones and Behavior, 61, 114-120.

Wilson, M., \& Daly, M. (1997). Life expectancy, economic inequality, homicide, and reproductive timing in Chicago neighbourhoods. British Medical Journal, 314, 12711274.

Wosick-Correa, K. (2010). Agreements, rules and agentic fidelity in polyamorous relationships. Psychology \& Sexuality, 1, 44-61.

Zeigler-Hill, V., Welling, L. L., \& Shackelford, T. K. (2015). How can an understanding of evolutionary psychology contribute to social psychology? In V. Zeigler-Hill, L. L. M. Welling, \& T. K. Shackelford (Eds.). Evolutionary perspectives on social psychology, (pp. 3-12). New York: Springer. 
Table 1

Mean differences between monogamous and primary partner evaluations, and mean differences between monogamous and secondary partner evaluations for overall, domain, and category level mate retention measures.

\begin{tabular}{llccccc} 
Monogamous & \multicolumn{3}{c}{ Primary } & \multicolumn{3}{c}{ Secondary } \\
M & SD & M & SD & $d$ & M & SD
\end{tabular}

$\begin{array}{lllllllll}\text { Overall scores }^{\text {a }} & \mathbf{3 1 . 3 6} & 9.46 & \mathbf{2 8 . 3 6} & 9.47 & 0.32 & \mathbf{2 0 . 0 4} & 10.68 & 1.12\end{array}$

Domain scores

$\begin{array}{lcccccccc}\text { Intersexual manip. }^{\text {b }} & \mathbf{2 1 . 6 5} & 7.02 & \mathbf{1 9 . 8 0} & 7.22 & 0.26 & \mathbf{1 3 . 8 8 *} & 8.14 & 1.03 \\ \text { Intrasexual manip. }^{c} & \mathbf{9 . 5 3} & 3.59 & \mathbf{9 . 1 7} & 3.16 & 0.11 & \mathbf{6 . 2 7 *} & 3.21 & 0.96\end{array}$

Category scores

$\begin{array}{lcccccccc}\text { Direct Guarding }^{\text {d }} & \mathbf{1 . 4 0} & 2.16 & \mathbf{1 . 0 8} & 1.65 & 0.17 & \mathbf{0 . 4 9 *} & 1.18 & 0.55 \\ \text { Intersexual Neg. Ind. }^{\mathrm{e}} & \mathbf{3 . 2 5} & 3.23 & \mathbf{2 . 6 5} & 3.69 & 0.17 & \mathbf{1 . 3 9} * & 3.31 & 0.57 \\ \text { Positive Ind. }^{\mathrm{e}} & \mathbf{1 7 . 0 0} & 3.86 & \mathbf{1 5 . 8 2} * & 3.85 & 0.31 & \mathbf{1 1 . 9 7 *} & 5.38 & 1.09 \\ \text { Public Signals }^{\mathrm{d}} & \mathbf{8 . 5 3} & 3.10 & \mathbf{8 . 3 6} & 2.82 & 0.06 & \mathbf{5 . 7 1} * & 3.12 & 0.91 \\ \text { Intrasexual Neg. Ind. }^{\mathrm{d}} & \mathbf{1 . 0 0} & 1.35 & \mathbf{0 . 8 2} & 1.22 & 0.14 & \mathbf{0 . 5 5} * & 0.92 & 0.40\end{array}$

*indicates a significant difference $(p<.05)$ compared to monogamous partner evaluations.

Absolute score range: ${ }^{\mathrm{a} 0} 0-114,{ }^{\mathrm{b}} 0-78,{ }^{\mathrm{c}} 0-36,{ }^{\mathrm{d}} 0-18,{ }^{\mathrm{e}} 0-30$. 
Table 2

Mean differences between primary and secondary partner evaluations for overall, domain, and category level mate retention measures.

Overall scores $^{\mathrm{a}}$

Primary

Secondary

M SD

$\mathrm{M} \quad \mathrm{SD} \quad d$

Domain scores

Intersexual manip. ${ }^{b}$

$19.16 \quad 6.75$

$\begin{array}{lll}13.00 & 7.23 & 0.89\end{array}$

Intrasexual manip. ${ }^{\mathrm{c}}$

$9.03 \quad 3.29$

$\mathbf{5 . 9 2} \quad 3.04 \quad 0.98$

Category scores

$\begin{array}{lccccc}\text { Direct Guarding }^{\mathrm{d}} & \mathbf{1 . 0 1} & 1.53 & \mathbf{0 . 3 6} & 1.02 & 0.51 \\ \text { Intersexual Neg. Ind. }^{\mathrm{e}} & \mathbf{2 . 3 1} & 3.14 & \mathbf{0 . 9 2} & 2.69 & 0.65 \\ \text { Positive Ind. }^{\mathrm{e}} & \mathbf{1 5 . 6 2} & 3.85 & \mathbf{1 1 . 6 9} & 5.06 & 0.79 \\ \text { Public Signals }^{\mathrm{d}} & \mathbf{8 . 1 9} & 2.97 & \mathbf{5 . 3 6} & 2.96 & 0.89 \\ \text { Intrasexual Neg. Ind. }^{\mathrm{d}} & \mathbf{0 . 8 2} & 1.24 & \mathbf{0 . 5 5} & 0.94 & 0.22\end{array}$

Primary and secondary partners significantly differed on each measure $(p<.001)$ except Intrasexual Negative Inducements $(p=.070)$.

Absolute score range: ${ }^{\mathrm{a} 0} 0-114,{ }^{\mathrm{b}} 0-78,{ }^{\mathrm{c}} 0-36,{ }^{\mathrm{d}} 0-18,{ }^{\mathrm{e}} 0-30$. 
Table 3

Mean discrepancy between participants' self-rated mate and partner-rated mate value for primary and secondary partners.

\begin{tabular}{lcccc} 
& \multicolumn{2}{c}{ Primary } & \multicolumn{2}{c}{ Secondary } \\
& & SD & M & SD \\
& $\mathbf{- 1 . 0 9}$ & 1.61 & $\mathbf{- 0 . 6 4}$ & 2.12 \\
Overall Desirability* & $\mathbf{- 0 . 9 2}$ & 1.90 & $\mathbf{0 . 7 7}$ & 2.81 \\
Desirability as Long-term Mate* & $\mathbf{- 1 . 1 9}$ & 1.67 & $\mathbf{- 1 . 0 1}$ & 1.91 \\
Physical Attractiveness & $\mathbf{0 . 1 2}$ & 2.65 & $\mathbf{- 0 . 0 1}$ & 2.86 \\
Financial Prospects & $\mathbf{- 0 . 3 5}$ & 1.74 & $\mathbf{- 0 . 2 9}$ & 2.22 \\
Social Status & $\mathbf{- 0 . 7 2}$ & 1.73 & $\mathbf{- 0 . 6 9}$ & 2.05 \\
Fun/Interesting & $\mathbf{- 0 . 3 9}$ & 3.01 & $\mathbf{- 0 . 2 3}$ & 2.79 \\
Dominance & $\mathbf{- 1 . 0 3}$ & 1.98 & $\mathbf{- 0 . 9 4}$ & 2.15
\end{tabular}

*indicates a significant difference between primary and secondary partners $(p<.05)$. 